\title{
TOMBEAUX DES POÈTES: Crisântemos tardios
}

\author{
Sueli Barros Cassal
}

RESUMO: La rénovation des techniques du langage poétique, mise en oeuvre surtout à la fin du XXè siècle, avec l'oeuvre de Mallarmé, a creé un fossé entre le poète et la société. Ne parlant plus "la langue de la tribu", comme le dit Mallarmé à propos de Poe, le poète s'isole, créant une oeuvre qui ressemble à une bouteille jeteé à la mer. À qui, en fait, s'adresse le poète?

PALAVRAS-CHAVE: poesia, impotência, folha em branco, morte, memória, loucu$r a$, naufrágio.

Ninguém é pai de um poema sem morrer. Manoel de Barros

Foi-se o tempo em que multidões se acotovelavam para ouvir Píndaro ou disputavam clandestinamente os exemplares de Os Castigos (1853), de Victor Hugo. (MOUNIN, 1968, p. 10).

Os poetas modernos têm-se espatifado contra a rocha, afirma Octavio Paz (1990, p. 253). A idéia de naufrágio é recorrente na poesia. O "barco bêbado" de Rimbaud, a "barca bela" de Garrett, o soçobrar das palavras em transe, palavrasnautas, no Lance de dados, o pélago que se cicatriza sobre a desmesura de Ulisses, em busca do fim do mundo (vide Haroldo de Campos (1996) rescrevendo o canto XXVI do Inferno de Dante).

De Emily Dickinson a Púchkin, de Renato Russo aos Irmãos Campos, os poetas continuam malditos, como pensava um deles, Verlaine, que criou a expressão em 1888, ao escrever o livro Os Poetas Malditos, sobre a poesia de Tristan Corbière, Mallarmé e Rimbaud, entre outros.

Hölderlin/Scardanelli se pergunta, na elegia Pain et Vin: "Et ainsi dans l'attente, que faire pendant ce temps, que dire? Je ne sais pas, et à quoi bon les

Sueli Barros Cassal é graduada em letras modernas pela Universidade de Paris VII; doutoranda em literatura brasileira na UFRGS 
poètes au temps de la détresse". (Apud BLANCHOT, 1978, p. 334). Não achando resposta, refugiou-se mais da metade de sua longa vida na loucura. Idem Maupassant. Idem Nerval1 : El desdichado: "Je suis le ténébreux, le veuf, l'inconsolé (...). No "Canto ao homem do povo Charles Chaplin", o nauta literário Drummond continua a litania, falando do clown: "És o tenebroso, o viúvo, o inconsolado,/o corvo, o nunca mais, o chegado muito tarde a um mundo muito velho."

Iessiênin, impotente diante dos poderosos do dia, sem um padrinho na revista "Posto", enforcou-se aos trinta anos, depois de escrever a Maiakóvski, em letras de sangue, sua despedida em versos (Apud MAIAKÓVSKI, 1982, p. 108):

(...)

Adeus amigo, sem mãos nem palavras.

Não faças um sobrolho pensativo.

Se morrer, nesta vida, não é novo,

Tampouco há novidade em estar vivo.

Em sua resposta à morte de Iessiênin, Maiakóvski desabafa (1982, p. 113):

Os tempos estão duros

Mas, dizei-me,

para o artista:

os grandes,

anêmicos e anões,

onde,

escolheram

em que ocasião,

uma estrada

batida?

"Eu ia dizer: não há mais inquisição. É falso, é claro. O que desapareceu, é o teatro da perseguição, não a própria perseguição", diz Barthes (1981, p. 94).

Em nossa época, Baudelaire também seria um "outsider", e certamente morreria encovado nos seus prematuros quarenta e seis anos, falando das prostitutas, dos velhos, do vinho, dos venenos. Carne pútrida/charogne. "O mort, vieux capitaine, il est temps! levons l'ancre".

Mallarmé que, segundo Valéry (1930, p. 181), “elevou uma página à potência do céu estrelado", morreu com uma palavra entalada na garganta, palavra-travo, cultuando "a brancura, o silêncio e o vazio". Da agrafia de Mallarmé (BARTHES, 1972, p. 55), do sorvedouro, salvou-se apenas uma plumazinha? Mallarmé conseguiu realmente inscrever no caos uma constelação?

Rimbaud, o caminhante, "o homem de solas de vento", mandou a poesia ao diabo, estrela cadente na Abissínia, poeta-negociante, trânsfuga da cosmopoesia, cruzando desertos, com oito de ouro amarrado à cinta. Arrebenta-se contra a rocha aos trinta e sete anos, ele que no seu livro de estréia, já começa dizendo adeus, como

${ }^{1}$ Nerval, "El desdichado": "Je suis le ténebreux, le veuf, l'inconsolé/Le prince d'Aquitaine à la tour abolie; /Ma seule étoile est morte, et mon luth constellé/ Porte le soleil noir de la mélancolie". Apud Julia Kristeva, Soleil Noir Dépression et Mélancolie. Paris, Gallimard, 1987, p. 152. 
assinala Blanchot (1983, p. 162).

Fizeste muito bem em partir, Arthur Rimbaud! Teus dezoito anos refratários à amizade, à malevolência, à sordidez dos poetas de Paris, assim como ao ronrom de abelha estéril de tua família ardenense tresloucada, fizeste bem de malbaratá-los aos ventos do alto mar, de jogá-los sob a lâmina de sua precoce guilhotina. Fizeste bem em abandonar o bulevar dos indolentes, os botequins dos mija-liras, pelo inferno das feras, pelo comércio dos astutos e pelo bom dia dos simples. (RENÉ CHAR, 1962, p. 212. A trad. é nossa)

"A Tarde de um fauno", de Mallarmé, poema que, segundo Bandeira, renovou o gênero égloga, foi recusado por Anatole France. Que recusou igualmente um soneto de Verlaine. "Mallarmé e Verlaine foram excluídos do Parnasse que acolheu D'Artois, Delthil, Dujolier, Marc, Marrot, Grandmoujin, Pigeon e Popelin. Já ouvistes falar nesses nomes", pergunta Bandeira (1975, p. 62).

Os poetas já não falam, como outrora, "a língua da tribo". Em vão, na "Primeira Elegia", Rilke (1974, p. 9) lança seu grito de socorro, em busca de um interlocutor: "Quem, se eu gritasse, quem ouviria meu grito entre as hierarquias dos Anjos?"

Muitos preferiram a dis-solução, como diz Drummond no poema Homenagem, de As Impurezas do Branco (Apud BOSI, 1997, p. 150).

$\mathrm{O}$ poeta inglês Chatterton envenenou-se aos 18 anos.

Mandelstam, 46 anos, morto no frio da Sibéria.

Virgínia Woolf, menos atlética, teve que colocar pequenos seixos nos bolsos.

Emily Dickinson (1830/1836) só teve a edição completa de seus 1775 poemas em 1954 (Apud CAMPOS, 1986, p. 107).

Keats, o poeta-rouxinol, tísico, pobre, 26 anos. Hart Crane, 33 anos. René Crevel, 35 anos. Pavese, 48 anos.

À Deleuze (1997), na encruzilhada da literatura com a filosofia, bastou mergulhar de um modesto terceiro andar. "Todo acontecimento é uma cerração de gotas".

Como o Capitão de Whitman (s.d., p. 272), o poeta leva o navio ao porto, muitas vezes às custas da própria vida. A híbris desses criadores de mundos suga-lhes o próprio sopro. Mas, como Orfeu, apesar do corpo despedaçado, ainda assim fazem ouvir o seu canto. Ao "sol negro", à face escura dos poetas, responde a luz de sua poesia.

Mandelstam contesta a idéia de que o poeta seja o "pássaro dos céus", expressão oriunda de um verso de Púchkin. O poeta-pássaro desceu das alturas, mas é um desengonçado entre os homens, conforme expressa Baudelaire no poema L'albatroz.

Por que esse divórcio entre o poeta e a sociedade, se a poesia, na noite dos tempos, confundia-se com a função religiosa e chegou a ser considerada como a própria origem das línguas? (PAIXÃO, 1982, p. 20)

Mario Faustino lembra, nos seus “Diálogos Poéticos” (1977, p. 27-69), espécie de "Apologia da Poesia", que esta sempre condensou a memória de um povo, idéia que o aproxima de Eliot. Tal qual insetos de arcanas eras prisioneiros do âmbar, e uma vez descobertos, conservam intactas todas as características de espécies 
revolutas, assim a poesia condensa, em estado latente, toda memória da humanidade. A viagem criada por Cavafy (1996, p. 102-103) é a de Ulisses e de cada um de nós em particular. Tanto quanto memória, o dizer poético é um pensamento sobre o ser. Segundo Heidegger, a metafísica não evoluiu o suficiente para dar conta do pensamento que se inscreve nos dois magros livros de versos de Rilke ${ }^{2}$. Se tanto Rousseau quanto Vico $^{3}$ afirmam que a língua primeva se confundia com a poesia, por que o poeta moderno nada a contracorrente?

Rimbaud (1954, p. 271), na carta a Paul Demeny, de 15 de maio de 1871, conhecida como "Carta do Vidente", verdadeira deontologia poética, afirma que o poeta é um novo Prometeu que quer se medir aos deuses, roubando-lhes o fogo para insuflar a vida ("Donc le poète est vraiment voleur de feu"). O poeta não vai repetir o mundo, mas sim agenciar frases e imagens para recompor um edifício verbal único, que acrescenta ao mundo um ser novo, bafejado de eternidade, tal como a ilha, descoberta pelo Capitão no poema de Vigny, expande a geografia terrestre. Assim Mallarmé, em "Crise de vers" (1979, p. 368) assinala que a flor é "a ausente de todos os buquês", quer expressar esse poder fundador da poesia, que desperta na língua morta do dia-adia uma nova pulsação, presentação e não representação.

João Cabral de Melo Neto, no rastilho de luz de Mallarmé: "Antiode”:

Poesia, não será este

O sentido em que

Ainda te escrevo:

Flor! (te escrevo:

Flor! Não uma

Flor, nem aquela

Flor-virtude - em

Disfarçados urinóis).

Flor é a palavra

Flor, verso inscrito

No verso, como

Manhãs no tempo

(...)

\footnotetext{
2 "Pour une interprétation globale des Élegies et des Sonnets nous sommes non seulement non préparés mais encore non qualifiés", "Pourquoi des poètes?" In: Chemins qui ne mènent nulle part. Paris, Gallimard, 1980, p. 332.

3 "Faz-se da linguagem dos primeiros homens línguas de geômetras, e vemos que foram línguas de poetas", afirma Rousseau. In: Essai sur l'Origine des Langues, Apud Jacques Derrida, De la Grammatologie. Paris, Les Éditions de Minuit, 1967, p. 387. (...) Se os povos se fundaram com as leis, e, se as leis, entre os povos todos, foram ditadas em versos, já que as primeiras coisas dos povos também em versos se conservam, [segue-se como] necessária coisa que todos os primeiros povos foram de poetas", afirma Vico In: "Da Sabedoria Poética", Princípios de (uma) Ciência Nova. São Paulo, Abril Cultural, 1974, p. 119.
} 
O mesmo João Cabral que, em Pedra do sono (1939-1941) coloca como epígrafe o verso "solitude, recife, étoile..." do famoso soneto Salut, com que Mallarmé brinda os amigos num banquete, na Revista Plume. Tremendo, o poeta ergue a taça (coupe/vers/verre) e o banquete, a mesa, a toalha vão se transmutando no barco, na tela, na vela branca, a aventura literária rumo ao naufrágio. Viagem em que o poetanauta soçobra, só, nos recifes, diante do "blanc souci de notre toile".

E com o poema Salut, a idéia da impotência diante da folha em branco, dos recifes, dos escolhos da viagem, chegamos à obra em branco de Mallarmé. No chamado "Poema do cisne", o cigne/signe está preso na folha branca, no espelho branco do gelo da impotência, esse branco tão caro a Mallarmé, essas geleiras em que se enreda o cisne/poeta, por não saber ou não querer usar "a língua da tribo".

Segundo Mário Faustino (1977, p. 217), a poesia está em crise pelo menos desde o Mallarmé de "Um lance de dados...". Já para José Paulo Paes,

A poesia está morta

Mas juro que não fui eu

Eu até que tentei fazer o melhor que podia para salvá-la... ${ }^{4}$

O poeta moderno já não fala a linguagem dos deuses, nem mesmo a linguagem dos homens, para parafrasear Renato Russo. Numa frase que resume a guerra tácita do poeta nas entranhas da língua ("Lutar com palavras é a luta mais vã"), Breton desabafa: "No sentido mais geral do termo, passamos por poetas porque, antes de tudo, nos atacamos à linguagem, que é a pior convenção que existe" (Apud MESCHONNIC, 1985, p. 254).

O divórcio dos poetas modernos é o divórcio em relação à língua abastardada da comunicação. Segundo Bataille (1979, p. 157), o poeta oficia um holocausto no qual a vítima são as palavras. Eviscerando-as de seu sentido primeiro, "a poesia navega do conhecido para o desconhecido". Com uma linguagem apoplética, os poetas voltam-se contra a própria linguagem, fazendo a bricolagem do mundo, a partir de palavras-cacos, $p t y x^{5}$, que tendem para o desfalecimento do sentido.

E como citamos essa palavra mágica de Mallarmé, espécie de abracadabra da poesia moderna, lembramos que não é por acaso que um dossiê consagrado a ele pelo

${ }^{4}$ A poesia está morta mas juro que não fui eu. São Paulo, Duas Cidades, 1988, p. 9. É verdade que José Paulo Paes fez tudo para salvar a poesia, desde seus próprios versos, suas traduções, sua poesia para crianças e seus ensaios. Inspirado em Mario Faustino, repisa a idéia da poesia como perigo. Muito embora as editoras alardeiem novas edições, a poesia não sai do limbo A Editora Sette Letras, por exemplo, editou nos últimos três anos mais de 50 livros de poesia, a maioria inédita. CDs com gravações de poesia e espetáculos de teatro são novas modalidades de divulgação da poesia no Brasil. Cf. reportagem "A hora da poesia", Revista Manchete, 24/7/1997.

${ }^{5} \mathrm{O}$ "soneto em X" de Mallarmé, que é na verdade um soneto sem título, já deu muito pano para manga, devido a sua rima em X (a incógnita) e em OR (o ouro, com toda a reverberação esotérica que comporta). Curiosamente, em sua tradução desse poema, Octavio Paz reduziu o número de " $\mathrm{x}$ ": dos 6 originais em Mallarmé, só constam 2 na tradução de Paz. Das 8 rimas em "or", Paz recria 3. Paz sacrifica inclusive a palavra "ptyx", que traduz por "conca". Já a tradução de Augusto de Campos é mais rica, pois quase recria a arquitetura original do "x" e do "or": 5 "x", 1 "is" e 6 "or". Cf. "Stéphane Mallarmé: O soneto em ix”, In: Signos em Rotação. São Paulo,Perspectiva, pp. 185-200. 
Magazine littéraire, em 1975, intitulava-se "Mallarmé le patron". Patrono de quem? Modelo de quem? Padroeiro de quem? De toda a poesia moderna. ${ }^{6}$

Mallarmé (1979, p. 366) já falava dessa dissolução do poeta, que faz eco à poesia de Drummond que citamos no início. "A obra pura implica o desaparecimento elocutório do poeta, que cede a iniciativa às palavras, pelo choque de sua desigualdade mobilizadas. Elas se iluminam de reflexos recíprocos como um virtual rastilho de luzes sobre pedrarias".

Não é por acaso que Drummond, numa seção intitulada "Palavra", do livro Lição de coisas, fecha "Isto é aquilo", com a concha de Mallarmé, do seu poema, muito mais que enigma, mistério, o poema em x. Sobre esse poema, Haroldo de Campos (1992, p. 54) afirmou: "poema-dicionário dos acasos da composição, a girar sobre si mesmo num eixo mallarmaico."

Éluard (1967, p. 153): La terre est bleue comme une orange Jamais une erreur les mots ne mentent pas.

A loucura sempre rondou esses criadores de mundos verbais. Mallarmé, certa feita, perguntou a Valéry se "Um lance de dados..." não era um ato de demência (VALÉRY, 1930, p. 180). Ossip Mandelstam afirma, porém, que a analogia entre o poeta e o desatinado é apenas aparente. Normalmente se tacha de louco aquele que, na falta de interlocutores, fala com a natureza ou com os objetos. Convém lembrar o poeta Francisco, de Assis, que falava aos pássaros e Santo Antonio, que falava aos peixes.

Álvares de Azevedo, em “Um cadáver de Poeta”, também coloca a questão da loucura do poeta:

De que vale um poeta - um pobre louco

Que leva os dias a sonhar - insano

Amante de utopias e virtudes

E, num tempo sem deus, ainda crente?

\footnotetext{
${ }^{6}$ Entre os inúmeros exemplos da influência de Mallarmé na poesia brasileira, fiquemos com Ziraldo. Pois bem, em Crise de vers, Mallarmé fala que as línguas são imperfeitas pois falta a suprema e, assim, o verso tem sua chance, ele "filosoficamente remunera o defeito das línguas". Essa idéia está em $O$ menino quadradinho, livro normalmente adotado nas sextas séries, mas como remata Ziraldo: "O menino quadradinho é "um livro como a vida. Só é para crianças no começo". Vamos ver como Ziraldo leu Mallarmé, como adaptou em clave infantil a idéia de que o verso remunera o defeito das línguas. Diz Ziraldo: "O menino entendeu: Entendeu que existem palavras, por exemplo, que são palavras leves de coisas pesadas [trevas, inveja] e palavras pesadas de coisas leves [balão, algodão], palavras bonitas de coisas feias e palavras feias de coisas bonitas [cudelume]... Entendeu que as palavras podem viver sozinhas e, todas lindas, se reunirem num jardim de palavras sem ter que ser nome de nada, só palavras, quebranto, paladar, crisântemo, barco, celacanto, bardo, sânscrito, parto, porto, trocadeiro, fortaleza, ileso, amor." E ainda reencontramos Ziraldo, rematando seu livro, falando do Branco, tão caro a Mallarmé: "E tudo ficou branco. Branco! O branco é, pois, o vazio, o nada. o Fim. Mas o branco é também o Começo, pois o branco é a Luz e a Luz foi a primeira coisa que se fez (Fiat lux, lembram-se?). Logo, se o branco e, ao mesmo tempo, o Fim e o Começo, o Fim é o Começo. Lógico! E o que é que está no Começo de tudo? O que está no Começo é a palavra!".
} 
A poesia é de certo uma loucura;

Sêneca o disse, um homem de renome.

É um defeito no cérebro... Que doudos!

Em suma, a quem o poeta se endereça?

O poeta Alfred de Vigny (1948, p. 210), em seu discurso no ingresso à Academia de Letras, em 1845, escreve a Defesa Obstinada da Poesia e dos Poetas, mostrando que o poeta não habita uma torre de marfim. Nos seus Poemas Filosóficos, volume póstumo, encontramos o poema “A garrafa jogada ao mar", de 1853. Nele, o capitão perscruta o pólo, seu navio soçobrou, as águas lhe chegam aos joelhos. É o naufrágio. Com a sabedoria do amor fati, o capitão joga a garrafa ao mar e ...

Sorri imaginando que esse frágil frasco

Levará seu pensamento e seu nome até o porto,

Que com uma ilha desconhecida ele expande a terra,

Que assinala um novo astro e o confia à sorte,

Oxalá Deus permita que as águas insanas

Aniquilem navios, mas nunca pensamentos:

E que com uma garrafa venceu a morte.

Mandelstam também fala dessa mensagem enviada dentro da garrafa e cujo destinatário é quem a encontrar. Quando lemos os versos abaixo, será necessário saber que são de Píndaro ${ }^{7}$, escritos há 2.500 anos? Na verdade eles são atuais, escritos para nós, aqui e agora, e para todos aqueles que um dia, depois de nós, os encontrarem.

Efêmeros! que somos?

que não somos? O homem

é o sonho de uma sombra.

Mas quando os deuses lançam

sobre ele a sua luz,

claro esplendor o envolve

e doce é então a vida.

Com esses versos, acreditamos que Píndaro realizou os desígnios da poesia, retomados por Mario Faustino: ensinar, deleitar e COMOVER.

\section{BIBLIOGRAFIA}

BANDEIRA, Manuel. Seleta em Prosa e Verso. Moraes de Emanuel (Org.). Rio de Janeiro, José Olympio, 1975.

BARTHES Roland. Le dégré zéro de l'écriture. Paris, Éditions du Seuil, 1972: "L'écriture et le silence".

. Essais Critiques. Paris, Éditions du Seuil, 1981: "Le dernier des écrivains heureux".

7“O sonho de uma sombra”, Poesia Grega e Latina. São Paulo, Cultrix, 1964, p. 115. Traduzido por Péricles Eugênio da Silva Ramos. 
BATAILLE, Georges. L'Expérience Intérieure. Paris, Gallimard, 1979: "Digression sur la poésie et Marcel Proust".

BLANCHOT, Maurice. L'espace littéraire, Paris, Gallimard, 1978. . Faux pas. Paris, Gallimard, 1983: "Après Rimbaud".

BOSI, Alfredo. O Ser e o Tempo da Poesia. São Paulo, Cultrix, 1997.

CAMPOS, Augusto de. O anticrítico. São Paulo, Companhia das Letras, 1986: "Emily: o difícil anonimato".

CAMPOS, Haroldo de. Metalinguagem e outras metas. São Paulo, Perspectiva, 1992. . Sobre Finismundo - A última viagem, Rio de Janeiro, Sette Letras, 1996.

CAVAFY, Constantin. Poèmes. Paris, Gallimard, 1996.

CHAR, René. Fureur et Mystère. Paris, Gallimard, 1962.

DELEUZE, Gilles. L'oiseau philosophie. Paris, Seuil, 1997.

ÉLUARD, Paul. Capitale de la douleur. Paris, Gallimard, 1967.

FAUSTINO, Mario. Poesia-experiência. São Paulo, Perspectiva, 1977: "Poética: Diálogos de oficina".

MAIAKÓVSKI . Poemas. São Paulo, Perspectiva, 1982.

MALLARMÉ. Oeuvres Complètes. Paris, Gallimard, Bibliothèque de la Pléiade, 1979: "Crise de vers".

MESCHONNIC. Les états de la poétique. Paris, PUF, 1985.

MOUNIN, Georges. Poésie et société. Paris, PUF, 1968.

PAIXÃO, Fernando. O que é poesia? São Paulo, Brasiliense, 1982.

PAZ, Octavio, El Arco y la lira. Mexico, Fondo de Cultura Economica, 1990.

RILKE, Rainer Maria. Les Élégies de Duino — Les Sonnets à Orphée. Paris, Seuil, 1974.

RIMBAUD, Oeuvres Complètes. Paris, Gallimard, Bibliothèque de la Pléiade, 1954.

VALÉRY, Paul. Variété II. Paris, Gallimard, 1930.

VIGNY, Alfred de. Oeuvres Complètes. Paris, Gallimard, Bibliothèque de la Pléiade, 1948, vol. I.

WHITMAN, Walt. Leaves of Grass, New York, New American Library, s.d..

ZIRALDO. O menino quadradinho. São Paulo, Melhoramentos, 1989. 